\title{
Glutathione S-transferases in human liver cancer
}

\author{
P C Hayes, L May, J D Hayes, D J Harrison
}

\begin{abstract}
An immunohistochemical study of glutathione S-transferase (GST) expression in hepatocellular carcinoma and cholangiocarcinoma is described. Unlike most animal models of hepatic malignancy pi class GST was not consistently overexpressed in hepatocellular carcinoma. This tumour type either predominantly expressed alpha class GST or failed to express GST. By contrast, cholangiocarcinoma always expressed pi class GST, presumably reflecting the tissue of origin, since in human biliary epithelium pi class GST is the predominant GST. The variable expression of pi class GST which was observed in hepatocellular carcinoma may reflect transformation of hepatocytes damaged by toxins, since this GST can be induced after a chemical insult such as alcohol. As well as indicating the biochemical heterogeneity of hepatocellular carcinoma with respect to GST, this study indicates the need for further study of the nature of inherent drug resistance in these tumour types.
\end{abstract}

The glutathione S-transferases (GST) are a complex supergene family of enzymes identified in a wide variety of tissues. These enzymes are believed to be important in detoxification, conjugating lipophilic electrophiles including a variety of carcinogens with glutathione. They also bind various non-substrate ligands including bile acids and bilirubin. ${ }^{12}$

The mammalian cytosolic GST isoenzymes are dimeric and can be divided into three principal gene families: alpha class, mu class, and pi class. In humans these families encode proteins with basic, near neutral, and acidic isoelectric points respectively. An additional membrane bound GST has been identified and named microsomal GST. ${ }^{34}$

We recently reported the distribution of both cytosolic and microsomal GST in the normal human liver. ${ }^{5} \mathrm{Pi}$ class GST is restricted to biliary epithelium whereas the other isoenzymes are found predominantly in hepatocytes. In many animal models of hepatocellular carcinoma there

Departments of Medicine PC Hayes

Pathology

L May

D J Harrison

and Clinical Chemistry, University of Edinburgh, Edinburgh

J D Hayes

Correspondence to:

Dr PC Hayes, Department of Medicine, Royal Infirmary,

Edinburgh EH39YW.

Accepted for publication

19 February 1991

\section{TABLE I GST expression in hepatocellular carcinoma}

\begin{tabular}{lllll}
\hline Patient No & alpha & $p i$ & $m u$ & microsomal \\
\hline 1 & - & - & - & + \\
2 & - & ++ & + & ++ \\
3 & ++ & - & - & ++ \\
4 & $+/++$ & ++ & + & + \\
5 & ++ & + & ++ & - \\
6 & + & - & - & - \\
7 & - & - & - & + \\
8 & + & - & $+l-$ & $+/-$ \\
9 & - & - & - & - \\
10 & - & - & $+/++$ & + \\
11 & + & - & ++ \\
\hline
\end{tabular}

$-=$ negative or trace, $+=$ weakly positive, $++=$ strongly positive. is overexpression of pi class GST ${ }^{67}$ This has led to the suggestion that pi class GST is a marker of preneoplasia and neoplastic transformation. However, biochemical studies on human hepatocellular carcinoma have not shown a uniform rise in pi class GST in all patients.

The purpose of the present study was to identify the distribution of GST isoenzymes in human hepatocellular carcinoma and compare it with cholangiocarcinoma and adjacent normal liver tissue where this was available.

\section{Methods}

Antisera to the cytosolic alpha, mu, and pi class enzymes and microsomal GST were raised in rabbits according to methods previously described. ${ }^{90}$ Specificity of the antisera from serum subsequently collected was determined by western blot analysis and radioimmunoassay.

Twelve cases of hepatocellular carcinoma and eight of cholangiocarcinoma were included in the present study. Wedge or needle biopsy specimens, fixed in formalin and embedded in paraffin, were obtained from archives in the Department of Pathology, University of Edinburgh. In four of the cases hepatocellular carcinoma adjacent to normal liver tissue was available for examination.

\section{IMMUNOSTAINING}

Tissue sections of $2 \mu \mathrm{m}$ were treated with $1 \%$ ( $\mathrm{vol} / \mathrm{vol}$ ) hydrogen peroxide in methanol for 20 minutes to block endogenous peroxidase activity. Sections were washed in Tris buffered saline ( $\mathrm{pH} \mathrm{7.6)}$ and treated with $20 \%$ normal goat serum (diluted in Tris buffered saline $\mathrm{pH} 7 \cdot 6$ ) for 15 minutes before being incubated with primary antiserum to GST (30 minutes 1:200 dilution at $\left.20^{\circ} \mathrm{C}\right)$. Normal rabbit serum $(1: 200)$ was used in place of the primary antibody for the negative controls. Incubation for 30 minutes with 1/200 biotinylated goat antirabbit antiserum (Dako, UK) $)^{11}$ was followed by streptavidin-peroxidase conjugate for 15 minutes (Dako, UK). Visualisation of antibody binding was by treatment with diaminobenzidine solution $(5 \mathrm{mg} / 10 \mathrm{ml}$ Tris buffered saline $0.1 \mathrm{~mol} / \mathrm{l}$ imidazole, $10 \mu \mathrm{l}$ hydrogen peroxide) for 10 minutes. Sections were rinsed in tap water, counterstained with Meyer's haematoxylin, and mounted before being examined by light microscopy.

\section{Results}

NORMAL HEPATIC TISSUE

Consistent with our previous report ${ }^{5}$ alpha class GST stained strongly in hepatocytes in the normal hepatic tissue, obtained in four cases adjacent to the hepatomas, with only occasional 


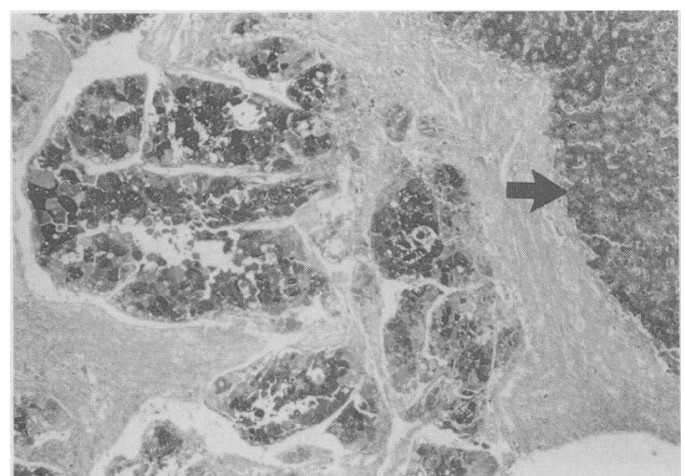

Figure 1: Staining for alpha class GST of hepatocellular carcinoma on left (strong but heterogeneous) and normal liver right (arrowed).

cells being stained in larger bile ducts. Pi class GST was present in biliary epithelium but not in normal hepatocytes. Mu class GST was present in all samples, moderately staining in three, and strongly staining in the other. Similarly, microsomal GST stained moderately in three and strongly in the remaining sample.

HEPATOCELLULAR CARCINOMA TISSUE (Table I) Alpha class GST stained strongly in only three of the 12 samples (Fig 1), moderately in two samples, and showed patchy moderate staining in two further specimens and weak or negative in the remaining five. Pi class GST stained strongly in two specimens, moderately in one, and was weak or negative in the remaining nine (Fig 2). $\mathrm{Mu}$ class GST stained strongly in two, moderately in three (Fig 3) and was weak or negative in the remaining seven. Microsomal GST stained strongly in three specimens, moderately in four, and showed a trace or was negative in the remaining five.

\section{CHOLANGIOCARCINOMA (Table II)}

In all eight of the cholangiocarcinomas studied pi class GST was readily shown and usually stained uniformly (Fig 4). Although alpha class was present in all cases, it was generally weak or present in scattered cells (Fig 5). Microsomal GST was identified in four tumours and was absent in four. Mu class GST expression was weak, but was seen in most cases.

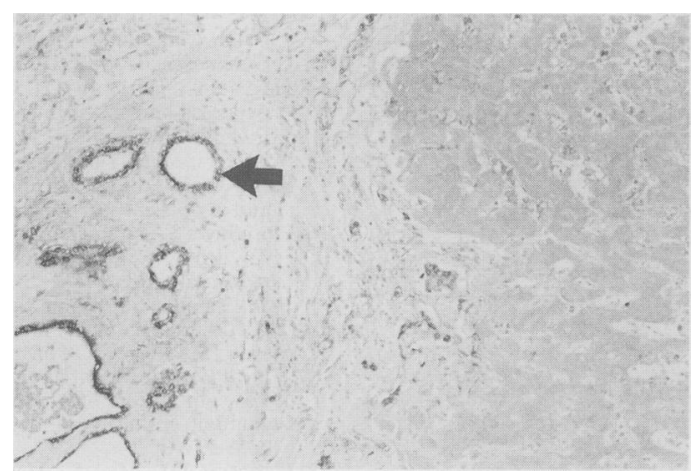

Figure 2: Staining for pi class GST in hepatocellular carcinoma showing positive staining in bile ducts (arrowed) but negative staining of malignant liver cells on right.

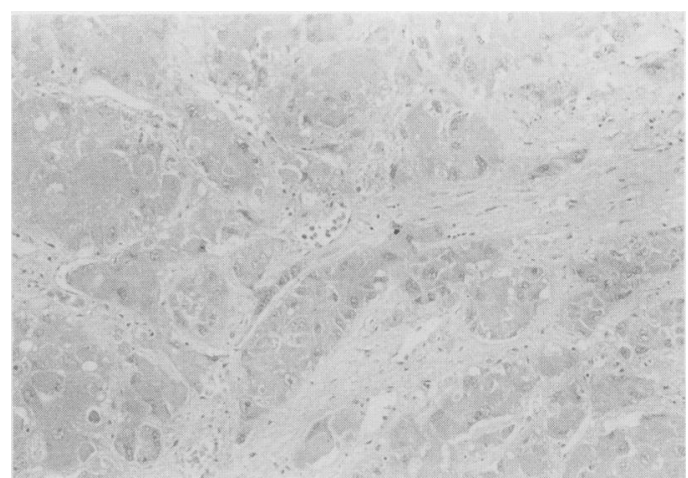

Figure 3: Staining for mu class GST in hepatocellular carcinoma showing weak postivity in all cells.

\section{Discussion}

We have shown that, whereas cholangiocarcinomas seem to retain a similar pattern of GST isoenzyme expression to that found in normal bile ducts, the expression of all the GST families in hepatocellular carcinomas is variable. In at least six cases of hepatocellular carcinoma there was a decrease in alpha class GST and in three cases malignant hepatocytes expressed pi class GST (unlike normal hepatocytes). The presence of pronounced pi class GST expression in only one quarter of cases is perhaps surprising in view of the frequent overexpression of this isoenzyme in many human tumours including lung, ${ }^{12}$ kidney, ${ }^{13}$ and pancreas. ${ }^{14}$

In most animal models of hepatocarcinogenesis there is uniform de novo expression of pi class GST by neoplastic hepatocytes. Pi class GST therefore has been regarded as a marker of preneoplasia, ${ }^{15}$ and its overexpression is thought to be involved in the acquisition of drug resistance. However, this thesis can be criticised on several grounds. Firstly, nitrosamine induced preneoplastic nodules in rat liver do not overexpress pi class GST when rats are fed hepatic peroxisome proliferators such as clofibrate. ${ }^{16}$ Secondly, although aflatoxin B1 induced preneoplastic hepatocyte nodules in rats overexpress pi class GST, it is the induction of an alpha class GST which confers resistance against the cytotoxic effects of aflatoxin B $1 .{ }^{17}$ Thirdly, hepatocytes in human liver biopsy specimens from patients with alcoholic liver disease express pi class GST. ${ }^{18}$ Alcoholic liver disease is not usually

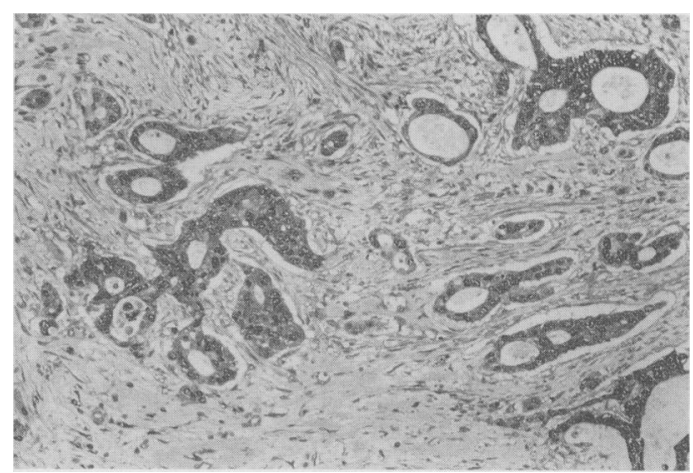

Figure 4: Staining for pi class GST in cholangiocarcinoma showing strongly positive staining of epithelial cells in ductlike formations. Stromal cells are also stained. 


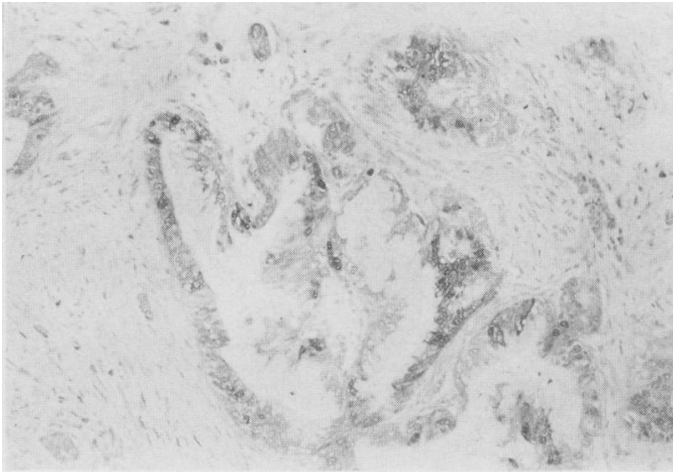

Figure 5: Staining for alpha class GST in cholangiocarcinoma showing focal positivity in malignant duct-like structures.

regarded as 'preneoplastic,' although a proportion of patients with alcoholic cirrhosis subsequently develop hepatocellular carcinoma. ${ }^{19}$ The biological importance of pi class GST expression therefore remains uncertain.

In the rat pi class GST expression in hepatomas may reflect oncogene activation since it has recently been reported that the APl binding sites exist at the $5^{\prime}$ end of the pi class GST gene. ${ }^{21}$ However, this consensus sequence does not seem to exist in the pi class human gene. Alternative explanations for occasional GST pi class expression in hepatocellular carcinoma may be dedifferentiation, since fetal hepatocytes have been shown to express pi class GST, ${ }^{20}$ or that the expression of pi class GST by hepatocytes results from a stress reponse mechanism. GST pi class has been shown to be induced by interferon. ${ }^{22}$

In $40 \%$ of the population from which this study was drawn mu class GST is not expressed in leucocytes, ${ }^{23}$ reflecting the known polymorphism of this enzyme first described in Australia. ${ }^{24}$ Patients who have the null polymorphism for this isoenzyme are more susceptible to lung cancer induced by cigarette smoke ${ }^{25}$ and may be more likely to develop chronic liver disease. ${ }^{26}$ The demonstration of mu class GST in seven of 12 hepatocellular carcinomas and four of eight cholangiocarcinomas does not suggest any protective effect of this enzyme, but assessment of the importance of this mu class GST polymorphism would require a much larger series. Although we have been able to phenotype subjects by immunohistochemistry, ${ }^{518} \mathrm{mu}$ class enzyme expression is variable between subjects since many are heterozygous for the null polymorphism. Genotyping is therefore a more precise and accurate screening investigation.

The expression of GST isoenzymes in liver tissue adjacent to hepatocellular carcinomas

TABLE II GST expression in cholangiocarcinoma

\begin{tabular}{lllll}
\hline Patient No & alpha & pi & $m u$ & microsomal \\
\hline 1 & - I++ H & ++ & - & - \\
2 & ++ H & ++ & + & + H \\
3 & F & ++ & - & + \\
4 & - H & ++ & - & - \\
5 & F+ & ++ H & - & - \\
6 & F & ++ & + & + \\
7 & F & + H & NA & - \\
8 & F & ++ & + & + \\
\hline
\end{tabular}

$-=$ absent or trace, $+=$ weakly positive, $++=$ strongly positive, $\mathrm{H}=$ heterogeneous, $\mathrm{F}=$ focal, $\mathrm{NA}=$ not available. seems to be normal. There is no consistent pattern of expression within hepatomas, although in general the expression of all the GST isoenzymes is reduced. This finding is contrary to the results reported in animal models of hepatocellular carcinoma where pi class GST and other classes are reported to be increased. In cholangiocarcinoma retention of pi, the predominant biliary GST isoenzyme, occurs and may explain the high concentration of pi class GST identified in the bile of patients with cholangiocarcinoma. ${ }^{27}$

Whether the prognosis of patients in whom GST expression is maintained in the hepatocellular carcinoma is improved compared with those in which GST expression is absent deserves further study.

We thank Mrs V Campbell for typing this manuscript. This work was supported by a grant from the Medical Research Council and the Scottish Hospital Endowment Research Trust.

1 Hayes JD, Pickett CB, Mantle TJ, eds. Glutathion -transferase and drug resistance. London: Taylor \& Francis, 1990

2 Mannervik B. The isoenzymes of glutathione S-transferases. Adv Enzymol Relat Areas Mol Biol 1985; 57: 357-417.

3 Morgenstern RF, Guthenberg C, De Pierre AW. Microsoma glutathione S-transferase. Purification, initial characterisation and demonstration that it is not identical to cystosolic glutathione S-transferases A, B and C. Eur F Biochem 1982; 128: $243-7$.

4 McLellan LI, Wolf CR, Hayes JD. Human microsoma glutathione S-transferase: its involvement in the conjugation glutathione S-transferase: its involvement in the conjugation

5 Hayes PC, Harrison DJ, Bouchier IAD, McLellan LI, Hayes JD. Cytosolic and microsomal glutathione S-transferase isoenzymes in normal human liver and intestinal epithelium. Gut 1989; 30: 854-9.

6 Tatematsu M, Mera Y, Inoue T, Satoh K, Sato K, Ito N Stable phenotypic expression of glutathione S-transferase placentral type and unstable phenotypic expression of $\gamma$-glutamyltransferase in rat liver preneoplastic and neoplastic lesions. Carcinogenesis 1988; 9: 215-20.

7 Harrison DJ, May L, Hayes JD, Neal GE. Glutathione $\mathrm{S}$-transferase localization in aflatoxin Bl treated rat livers. Carcinogenesis 1990; 11: 927-31.

8 Sherman M, Campbell JAH, Titmuss SA, Kew MC, Kirsch RE. Glutathione S-transferase in human hepatocellular carcinoma. Hepatology 1983; 3: 170-6.

9 Hayes JD, Mantle TJ. Use of immunoblot techniques to discriminate between the glutathione S-transferase Yf, Yk, $\mathrm{Ya}, \mathrm{Yn} / \mathrm{Yb}$ and $\mathrm{Yc}$ units and to study their distribution in extrahepatic tissues. Evidence of three immunochemically distinct groups of transferase in the rat. Biochem $\mathcal{F} 1986 ; 23$ 779-88.

10 Hayes JD, Gilleghan D, Chapman BJ, Beckett GJ. Purification of human hepatic glutathione S-transferases and the development of a radioimmunoassay for the measurement in plasma. Clin Chim Acta 1983; 134: 107-21.

$11 \mathrm{Hsu}$ SM, Raine L, Fanger H. Use of an avidin-biotinperoxidase complex (ABC) in immunoperoxidase techniques. A comparison between $A B C$ and unlabeled antibudy niques. A comparison between $\mathrm{ABC}$ and unlabeled antibod

12 Carmichael J, Forrester LM, Lewis AD, Hayes JD, Hayes PC Wolf CR. Glutathione S-transferase isoenzymes and Wolf CR. Glutathione S-transferase isoenzymes and
glutathione peroxidase activity in normal and tumor samples glutathione peroxidase activity in normal and tumor
from human lung. Carcinogenesis 1988; 9: 1617-21.

13 Harrison DJ, Kharbanda R, Bishop D, McLellan LI, Hayes JD. Glutathione S-transferase isoenzymes in human renal carcinoma demonstrated by immunochemistry. Carcinogenesis 1989; 10: 1257-60.

14 Hayes PC, Harrison DJ. Immunohistochemical analysis of pancreas and gastrointestinal tract in man. In: Hayes JD, Pickett CB, Mantle TJ, eds Glutathione S-transferases and drug resistance. London: Taylor \& Francis, 1990: +41-50.

15 Sato K. Glutathione S-transferases as markers of preneoplasia and neoplasia. Adv Cancer Res 1989; 52: 205-55.

16 Hosokawa S, Tatematsu M, Aoki T, Nakanowatari J, Igarastu T, Ito N. Modulation of diethylnitrosamine-initiated placental glutathione S-transferase positive preneoplastic placental glutathione S-transferase positive preneoplastic and neoplastic lesions by clofibrate, a hepatic

17 Hayes JD, Kerr LA Harrison DJ, Crons Neal GE. Preferential over-expression of the class alpha rat $\mathrm{Ya}_{2}$ glutathione S-transferase subunit in livers bearing aflatoxin-induced pre-neoplastic nodules. Biochem $\mathcal{F} 1990$ 268: $295-302$

18 Harrison DJ, May L, Hayes PC, Haque MM, Hayes JD. Glutathione $\mathrm{S}$-transferases in alcoholic liver disease. (iut 1990; 31: 909-12

19 MacSween RMN, Anthony PP, Scheuer PJ, eds. Pathology of the liver. 2nd ed. Edinburgh: Churchill Livingstone, 1987. 
20 Hiley C, Fryer A, Bell J, Hume R, Strange RC. The human glutathione $\mathrm{S}$-transferases. Immunohistochemical studies of the developmental expression of alpha- and pi-class isoenzymes in liver. Biochem $\mathcal{F} 1988 ; 254: 255-9$.

21 Okada A, Imagawa M, Sakai M, Muramatsu M. Functional cooperativity between two TPA response elements in undifferentiated F9 embryonic time cells. EMBOF 1990; 9 1131-5.

22 Adams DJ, Balkwill FR, Griffin DB, Hayes JD, Lewis AD, Wolf CR. Induction and suppression of glutathione Stransferases by interferon in the mouse. $\mathcal{F}$ Biol Chem 1987; 262: 4888-92.

23 Hussey AJ, Hayes JD, Beckett GJ. The polymorphic expression of neutral glutathione $S$-transferase in human mononuclear leukocytes as measured by specific radioimmunoassay. Biochem Pharmacol 1987; 36: 4013-5.

24 Board PG, Coggan M. BamHl and EcoRl restriction fragmen length polymorphisms at the glutathione S-transferase 3 locus. Nucleic Acids Res 1989; 17: 7550 .

25 Beattie EJ. Isoenzymes of glutathione transferase (class $\mathrm{mu}$ ) as a marker for the susceptibility to lung cancer: a follow up study. Carcinogenesis 1990; 11: 33-6.

26 Harada S, Abei M, Tanaka N, Agarwai DP, Goedde HW. Live glutathione S-transferase polymorphism in apanese and its pharmocet

27 Howie AF, Hayes PC, Bouchier IAD, Hayes JD, Beckett GJ. Glutathione S-transferase in human bile. Clin Chim Acto 1989; 184: 269-78. 